Izumi, Volume 7 No 2, 2018

e-ISSN: 2502-3535, p-ISSN: 2338-249X

Tersedia online di http://ejournal.undip.ac.id/index.php/izumi

\title{
IDIOM 'SARU' SEBAGAI REFLEKSI KONSEP PEMIKIRAN MASYARAKAT JEPANG TERHADAP MONYET
}

\author{
Devita Widyaningtyas Yogyanti \\ Bina Sarana Informatika Yogyakarta \\ devita.ded@bsi.ac.id
}

\begin{abstract}
Abstrak
Penelitian ini adalah sebuah penelitian linguistik antropologi dengan idiom yang menggunakan kata "saru"(monyet) sebagai objek kajiannya. Penelitian ini bertujuan untuk melihat konsep dasar pemikiran masyrakat tentang "saru”" (monyet) melalui idiom-idiomnya. Idiom-idiom yang menggunakan kata "saru" dikumpulkan melalui studi kepustakaan dari literatur-literatur yang memuat idiom dalam bahasa Jepang dan wawancara kepada orang Jepang yang ada di Yogyakarta. Fokus penelitian ini adalah hubungan antara makna literal dan makna metaforis dalam idiom yang menggunakan kata "saru". Hubungan makna ini ditelusuri menggunakan sudut pandang diakronis untuk melihat konsep pemikiran masyarakat Jepang tentang monyet. Dari hasil penelitian ditemukan 11 idiom yang menggunakan kata "saru”, yaitu sansaru, sarugi, sarugutsuwa, sarushibari, sarutsunagi, sarujie, sarugashikoshi, sarumane, sarushibai, saruboo dan saruni. Dari hubungan makna literal dan makna metaforis ke-11 idiom tersebut, diketahui bahwa masyarakat Jepang mempunyai 3 konsep pemikiran terhadap monyet, yaitu sebagai hewan yang sakral atau suci, hewan yang memiliki kekuatan magis untuk membuat sesuatu menjadi diam dan hewan yang mirip manusia.
\end{abstract}

Kata kunci :idiom; saru; konsep pemikiran

\begin{abstract}
(Title: Idiom 'Saru' as a Reflection of Japanese People Thinking Concept Towards Monkey). This research is an anthropological linguistic study that is conducted by examining the idioms that use the word "saru" (monkey) as the object of study. This study aims at analyzing the basic concepts of people's thought about the word "saru" (monkey) through the use of its idioms. The researcher collected the data of the idioms that use the word "saru" through literature studies that cover the literature containing Japanese idioms and interviews of Japanese people living in Yogyakarta. The focus of this research is the correlation between literal meaning and metaphorical meaning in idioms that contain the word "saru". The correlation of the meaning is traced using a diachronic perspective to see the concept of Japanese people's thought towards monkeys. According to the results of the study, the researcher found 11 idioms that use the word "saru", namely Sansaru, Sarugi, Sarugutsuwa, Sarushibari, Sarutsunagi, Sarujie, Sarugashikoshi, Sarumane, Sarushibai, Saruboo, and Saruni. From the relationship between the literal meaning and the metaphorical meaning of the 11 idioms, the result shows that Japanese people have 3 concepts towards monkey, which are as a holy and sacred animal, as an animal that possesses the magical power to make something quiet, and as an animal resembling the human being.
\end{abstract}


Izumi, Volume 7 No 2, 2018

e-ISSN: 2502-3535, p-ISSN: 2338-249X

Tersedia online di http://ejournal.undip.ac.id/index.php/izumi

Keywords: idiom; saru; the concept of thought

\section{PENDAHULUAN}

Dalam lingusitik antropologi, bahasa sebagai objek kajiannya dipandang sebagai suatu set simbolik yang merupakan representasi dari dunia (Duranti, 1997: 5). Bentuk fisik dari bahasa yaitu kata, gabungan kata, ataupun kalimat-kalimat memiliki suatu konsep makna yang merupakan refleksi pengetahuan manusia dari hal-hal yang dialaminya (Foley, 1997: 8). Namun, pengetahuan manusia yang sangat beragam sering kali tidak dapat diwujudkan melalui suatu bentuk fisik bahasa yang benar-benar mewakilinya. Oleh karena itu, manusia sering menggunakan bentuk ungkapan lain untuk menyampaikan pengetahuannya kepada orang lain.

Dalam istilah kebahasaan, bentuk penggunaan ragam bahasa yang berhubungan dengan ungkapan dimanifestasikan dalam berbagai bentuk, salah satunya adalah idiom. Idiom merupakan ragam ungkapan yang banyak dipakai oleh masyarakat dalam kehidupan sehari-hari dan bersifat 'teradat'. Maksudnya adalah, pembentukan idiom dipengaruhi oleh local wisdom yang merupakan kekhasan bahasa dari masyarakat setempat. Hal ini menyebabkan orang asing belum tentu dapat memahami makna idiom dari suatu masyarakat tertentu (Badudu dalam Hartati, 2002:3). Oleh karena itu, pada dua atau lebih negera yang berbeda, kata pembentuk idiom bisa diartikan secara berbeda, seperti kata monyet sebagai kata pembentuk idiom dalam Bahasa Indonesia dan Jepang.

Dalam bahasa Indonesia, kata monyet hanya muncul dalam satu idiom yaitu "cinta monyet" yang berarti cinta sepasang muda-mudi yang masih belia atau cinta yang hanya pura-pura. Dari idiom ini, dapat diketahui bahwa monyet dalam konsep pemikiran orang Indonesia merepresentasikan suatu ketidakseriusan ataupun kepura-puraan. Namun dalam Bahasa Jepang, penulis menemukan 11 idiom yang menggunakan kata monyet (saru). Jika mengingat bahwa pembentukan idiom dipengaruhi oleh local wisdom maka penggunaan kata sarudalam 11 idiom tersebut juga pasti dipengaruhi oleh local wisdom dan bukanlah suatu kebetulan. Maka dalam penelitian ini akan diungkap local wisdom masyarakat Jepang mengenai hewan monyet melalui idiomidiomnya.

Berdasarkan studi literasi terdahulu, ditemukan kajian serupa dengan penelitian ini. Pertama adalah kajian yang ditulis oleh R.Retno Dyah (2017) dalam Idiom Bahasa Jepang yang Menggunakan Nama Hewan. Dalam kajian ini, penulis membahas mengenai daftar idiom-idiom berunsur nama hewan yang masih tetap digunakan sampai sekarang. Dalam penelitian tersebut, idiom-idiom yang dikaji diteliti dari struktur sintaksis, makna literal dan makna idiomatiknya. Dari hasil penelitian diketahui bahwa terdapat 39 idiom berunsur nama hewan yang masih aktif digunakan oleh masyarakat Jepang hingga saat ini. Nama-nama hewan yang termuat dalam idiom-idiom tersebut memiliki makna idiomatis yang merepresentasikan konsep mengenai perasaan, tindakan, tingkah laku, kehidupan dan kondisi. Namun pada penelitian ini tidak ditemukan idiom yang menggunakan kata monyet.

Kajian kedua adalah penelitian mengenai perbandingan metafora yang menggunakan nama hewan di Cina dan Inggris dalam What Animals reveal about Grammar and Culture: A Study of Animal Mataphors in Mandarin Chinese and English (2011). Dalam penelitian ini, metafora yang diteliti digunakan untuk mengungkapkan tata bahasa dan budaya di Cina dan Inggris. Dari hasil penelitian ini, Shu dan Li mengungkapkan bahwa secara, tata bahasa, nama hewan dalam susunan kata yang membentuk metafora dapat digunakan sebagai denominal verb (verba yang berasal dari nomina). Sedangkan dari segi kultural, nama hewan dalam metafora 
Izumi, Volume 7 No 2, 2018

e-ISSN: 2502-3535, p-ISSN: 2338-249X

Tersedia online di http://ejournal.undip.ac.id/index.php/izumi

dapat merefleksikan sejarah kulturalsuatu bangsa.Masyarakat dari bangsa yang berbeda bisa mempunyai pandangan yang berbeda terhadap hewan yang sama. Misalnya, anjing dalam budaya Inggris mempunyai kesan yang baik, sedangkan dalam budaya Cina, anjing dinilai buruk oleh masyarakatnya. Namun, hewan dalam metafora di kedua bangsa tersebut secara umum digunakan sebagai refleksi kelakuan manusia.

Berbeda dari dua kajian sebelumnya, penelitian ini mempunyai objek penelitian yang lebih spesifik, yaitu hewan monyet yang muncul dalam idiom bahasa Jepang. Selain itu, dalam penelitian ini akan dijelaskan bagaimana dan mengapa kata monyet muncul dalam suatu idiom melalui penelusuran sejarah kultural bangsa Jepang. Melalui penelusuran sejarah kultural tersebut, pengalaman yang dialami masyarakat Jepang akan digunakan untuk menjelaskan hubungan makna literal dan metaforis yang terkandung dalam idiom-idiomnya.

Metafora sering diistilahkan dengan folk theory of the world yang merupakan suatu bentuk teori atau kerangka berfikir masyarakat untuk menjelaskan suatu kejadian di dunia atau suatu fenomena yang dialami manusia dalam kehidupannya. Suatu idiom yang mengandung unsur perbandingan dengan suatu hal, dapat digolongkan sebagai metafora. Sebagai contoh, frasa raja siang dapat dipandang sebagai idiom jika hanya dilihat dari maknanya. Namun dengan adanya perbandingan dengan sesuatu yang lain, maka raja siang juga dapat digolongkan ke dalam metafora (Hartati, 2002: 16-17). Dilandasi konsep tersebut maka idiom yang dikaji dalam makalah ini akan dikaji menggunakan teori metafora. Dalam penelitian ini, metafora dipandang dari sudut pandang diakronis. Dari sudut pandang ini, idiom dapat dipandang sebagai metafora yang sudah mati. Maksudnya adalah idiom tersebut pada awalnya adalah suatu metafora, namun karena penggunaan yang konstan, maka metafora tersebut berubah menjadi sebuah batang leksikal berupa idiom (Bilig, 2005: 460).

Teori retorikal mengatakan bahwa sebenarnya bahasa dipenuhi oleh mataforametafora yang telah 'mati' (Richard dalam Bilig, 2005: 460). Menurut para penganut teori retorikal abad ke 18 seperti George Campbell, pada awalnya metafora menciptakan gambaran visual terhadap suatu hal dengan sangat jelas. Akan tetapi, metafora-metafora yang telah menjadi sangat umum di masyarakat akibat pemakaian yang terus-menerus akhirnya diterima oleh budaya masyarakat setempat sebagai 'arti literal dari dunia'. Dengan kata lain, metafora dapat dileksikalkan dan berubah menjadi suatu kata yang mempunyai arti leksikal daripada arti metaforis. Lebih jauh lagi, Goally menyampaikan bahwa metafora bisa menjadi tidak aktif karena dileksikalkan dan digunakan bersama oleh masyarakat sebagai suatu yang disepakati dalam sense literal. Namun walaupun demikian, Goally menambahkan bahwa arti asli dari metafora yang sudah tidak aktif tersebut masih bisa dikembalikan (Bilig, 2005:461).

Seed dan Palmer (dalam Setyari, 2013: 16) berpendapat bahwa ada tiga pokok penting dalam metafora yaitu:

1. tenor (ranah target): konsep yang dideskripsikan

2. vehicleatau citra (ranah sumber): konsep yang mendeskripsikan atau mengiaskan tenor.

3. ground, sense atau persamaan: relasi persamaan antara tenor dan vehicle (dapat berupa persamaan bentuk, tempat, sifat, motif, konsep, fungsi dan sosial budaya).

Dalam metafora, ranah konsep suatu hal (ranah sumber) digunakan untuk menjelaskan ranah konsep hal lainnya (ranah target). Ranah sumber biasanya diambil dari pengalaman familiar seharihari ataupun benda-benda yang secara fisik 
ada di alam nyata, sedangkan ranah target biasanya bersifat lebih abstrak. Ranah target ini bisa juga berupa pengalaman atau kejadian yang lebih terpisah dari dunia fisik sehari-hari (Fernandez dalam Foley, 1997: 182). Penentuan ranah sumber tidak selamanya bersifat arbitrer. Penentuan ini didasarkan pada pemahaman individu terhadap kedua ranah tersebut. Pilihan ini akhirnya akan menjelaskan mengenai konsep apa yang akan ditransfer dan bagaimana cara seseorang dalam memahami ranah target (Foley, 1997: 183). Metafora juga merupakan sebuah ekspresi budaya dalam komunikasi. Hal ini karena metafora dianggap sebagai alat yang efektif untuk menginterpretasikan suatu hal yang abstrak dalam bentuk harfiah (tekstual) dan lebih efisien karena dapat menjelaskan konsep, ide, gagasan dengan lebih komprehensif, ringkas dan kontekstual meskipun diungkapkan secara harfiah (tekstual) (Palandi, 2013: 266).

Dari latar belakang dan berbagai uraian di atas, maka ada dua permasalahan yang akan dikaji dalam penelitian ini. Pertama adalah mengenai makna literal dan metaforis dari idiom "saru", kedua adalahmengenai konsep pemikiran masyarakat Jepang mengenai monyet yang dikaji melalui hubungan antara makna literal dan dan metaforis idiom "saru".

\section{METODE PENELITIAN}

Permasalahan dalam penelitian ini akan dikaji dari melalui sudut pandang teori metafora. Dalam hal ini, akan dilihat ranah target atau konsep yang dilambangkan, ranah sumber yang digunakan untuk membentuk idiom dan relasi yang menghubungkan ranah sumber dan ranah target dari idiom-idiom tersebut. Relasi antara ranah sumber dan ranah target akan ditelaah dengan merujuk pada fakta-fakta budaya dan sejarah yang dikumpulkan melalui studi pustaka.

\section{HASIL DAN PEMBAHASAN} 3.1 Arti Literal dan Metaforis Idiom yang Menggunakan Kata "Saru"
Daftar gabungan kata di bawah ini merupakan idiom yang menggunakan kata saru dalam Bahasa Jepang. Arti leksikal dari idiom di bawah ini diambil dari kamus Besar Bahasa Jepang Köjien tahun 1999 dan kamus Bahasa Jepang Mutakhir Meikyō Kokugo Jiten 2009.

a. sanzaru

Idiom ini berasal dari kata san 'tiga'dan saru 'monyet'. Idiom ini merupakan filosofi yang berarti tiga perintah dewa, yaitu tidak melihat hal-hal buruk (mizaru), tidak mendengar hal-hal buruk (kikizaru) dan tidak berbicara halhal-hal buruk (iwazaru). Masyarakat Jepang menggunakan kata san yang berarti 'tiga' untuk menggambarkan tiga ajaran tersebut. Sedangkan kata saru digunakan untuk merepresentasikan dewa.

b. sarugi

Sarugi berasal dari kata saru yang berarti monyet dan $k i$ yang berarti pohon. Idiom yang secara harfiah memiliki arti 'pohon monyet' ini merujuk pada tiang atau pohon yang digunakan untuk menambatkan kuda di kandang kuda.

c. sarugutsuwa

Sarugutsuwa berasal dari kata saru 'monyet' dan gutsuwa 'tali kekang'. Idiom ini merujuk pada benda yang disumpalkan ke mulut supaya seseorang tidak bisa bicara ataupun berteriak. Dengan kata lain, benda ini adalah benda yang digunakan agar seseorang menjadi diam (tidak liar).

d. sarushibari

Sarushibari berasal dari kata saru 'monyet'danshibari' ikatan'. Secara harfiah makna gabungan kata ini berarti ikatan monyet. Idiom ini merujuk pada suatu keadaan seseorang dengan tangan dan kaki yang terikat.

e. sarutsunagi

Sarutsunagi ini berasal dari kata saru 'monyet' dan tsunagi 'pengencangan'. Secara harfiah gabungan kata ini diartikan dengan 'pengencangan monyet'. Gabungan kata ini merujuk pada keadaan seseorang dengan posisi kedua tangan terikat ke belakang pada pohon ataupun tiang. 
Izumi, Volume 7 No 2, 2018

e-ISSN: 2502-3535, p-ISSN: 2338-249X

Tersedia online di http://ejournal.undip.ac.id/index.php/izumi

\section{f. Sarugashikoshi}

Sarugashikoshi berasal dari kata saru 'monyet' dan kashikoi 'bijaksana. Secara harfiah gabungan kata ini dapat diartikan sebagai 'kebijaksanaan monyet'. Idiom ini digunakan untuk menyebut sifat seseorang yang pintar tetapi licik.

g. sarujie

Sarujie ini berasal dari kata saru 'monyet'dan jie 'intelegensi'. Secara harfiah, gabungan kata ini dapat diartikan sebagai intelegensi monyet. Idiom 'sarujie' merujuk pada suatu pemikiran yang nampak meyakinkan di luarnya namun sebenarnya tidak.

h. sarushibai

Sarushibai berasal dari kata saru 'monyet' dan shibai 'drama'. Secara harfiah gabungan kata ini dapat diartikan sebagai pertunjukan monyet. 'Sarushibai' mempunyai dua makna yaitu 1.) pertunjukkan yang buruk dan 2.) perencanaan yang bodoh.

i. saruni

Saruni berasal dari kata saru 'monyet' dan $n i$ 'mirip. Secara harfiah, gabungan kata ini dapat diartikan sebagai mirip monyet. Idiom ini merujuk pada suatu fenomena yang terjadi bila ada dua orang yang mirip tetapi bukan saudara kandung.

j. saruboo

Saruboo ini berasal dari kata saru 'monyet'dan boo'pipi. Secara harfiah gabungan kata ini dapat diartikan sebagai pipi monyet. Idiom ini merujuk pada pipi yang membesar karena ada banyak makanan di dalam mulut.

$k$. sarumane

Sarumane berasal dari kata saru 'monyet' dan maneru 'meniru'. Secara harfiah gabungan kata ini dapat diartikan sebagai monyet yang suka meniru. Idiom ini merujuk pada suatu perbuatan meniru orang lain tanpa berfikir.

Dari kesebelas idiom di atas, arti literal dari idiom-idiom tersebut secara umum dapat dibagi ke dalam tiga konsep besar, yaitu hal yang berhubungan dengan dewa, hal berhubungan dengan membuat seseorang menjadi diam atau tidak dapat bergerak dan hal yang hubungan dengan sifat-sifat dan kejadian-kejadian khas yang dialami manusia.

\subsection{Konsep Pemikiran Masyarakat Jepang Terhadap Monyet Melalui Relasi Makna Literal dan Metaforis Idiom "Saru"}

Dalam berbagai bahasa di dunia, hewan sering digunakan sebagai metafora dari suatu hal yang dialami manusia (Wijana, 2013: 26), termasuk dalam Bahasa Jepang. Hal ini dikarenakan dalam budaya Jepang, terdapat suatu konsep yang menyatakan bahwa dunia ditinggali bersama oleh manusia, hewan, tumbuhan, arwah, setan, serta dewa. Oleh sebab itu, hewan sebagai salah satu penghuni dunia memiliki peran yang nyata dan bukan sekedar imajinasi manusia (Mayer, 1981: 1). Peran nyata hewan sebagai pengalaman nyata masyarakat Jepang akhirnya banyak digunakan masyarakat Jepang sebagai representasi dari hal-hal lain yang diketahuinya.

Merujuk pada hal di atas, maka dapat diketahui bahwa penggunaan kata saru dalam idiom-idiom di atas bukanlah suatu kebetulan. Merujuk pernyataan Foley (1997: 183) penentuan saru sebagai ranah sumber menunjukkan adanya konsep pemahaman tertentu masyarakat Jepang baik terhadap monyet maupun ranah target yang dijelaskan oleh kata saru. Pilihan ranah sumber untuk menjelaskan ranah target dipengaruhi oleh pengalaman manusia (Kövecses dalam Prayogi, 2013: 777), dalam hal ini pengalaman budaya masyarakat Jepang. Pengalaman tersebut selanjutnya membentuk suatu konsep pemikiran terhadap monyet yang akhirnya menciptakan ground atau relasi persamaan antara vehicle dan tenor-nya. Hal ini sesuai dengan pernyataan Prayogi (2013: 776777) mengenai metafora, yaitu metafora 
utamanya tidak terdapat pada bahasa tetapi pada pemikiran.

Dari hasil penelitian, diketahui bahwa masyarakat Jepang memiliki 3 konsep pemikiran terhadap monyet, yaitu sebagai hewan yang sakral dan suci, sebagai hewan yang memiliki kemampuan magis untuk membuat sesuatu menjadi diam dan sebagai hewan yang mirip manusia.

\section{a. Monyet Sebagai Hewan yang Suci dan Sakral}

Konsep pemikiran masyarakat Jepang terhadap monyet sebagai hewan yang suci dan sakral terlihat dalam idiom Sanzaru. Dapat dikatakan, konsep ini merupakan konsep pemikiran paling tua terhadap monyet. Kata sanzaru mempunyai arti literal tiga monyet dan arti metaforis tiga perintah dewa. Konsep pemikiran ini bisa jadi lahir kepercayaan masyarakat Jepang terhadap dewa monyet. Kepercayaan yang mengganggap monyet adalah representasi dewa telah ada dalam masyarakat Jepang sejak ribuan tahun lalu. Dalam kepercayaan tersebut, monyet dipercaya sebagai mediator atau pembawa pesan yang bertugas menghubungkan dunia supranatural dengan dunia manusia. Ada yang meyakini bahwa monyet adalah pembawa pesan dari dewa gunung (Origuchi dan Yanagita via OhnukiTierney,1984:280). Selain itu, ada juga yang mengatakan bahwa monyet merupakan salah satu dewa terpenting dalam jajaran dewa-dewa dalam kepercayaan di Jepang (Blacker dan Yanagita via Ohnuki-Tierney, 1984:280).

Dalam Kojiki, dokumen tertua di Jepang, disebutkan bahwa dewa yang bernama Saruta Biko mempunyai ciri-ciri seperti monyet Jepang.Saruta Biko diidentikkan sebagai monyet, karena kata 'saru' dalam 'Saruta Biko' berarti monyet. Selain itu, ciri-ciri fisik Saruta Biko digambarkan seperti monyet Jepang yang berbokong merah dan berekor pendek (Shimonaka via Ohnuki-Tierney, 1984:280). Dalam dokumen tersebut,
Saruta Biko digambarkan sebagai dewa yang memandu anak keturunan para dewa di kayangan untuk mengurus dunia bawah (dunia manusia) (Philippi dan Shimonaka via Tierney:1984:280). Dewa ini adalah dewa dalam agama Shinto yang digambarkan mempunyai hidung serta tujuh lengan yang panjang. Dalam mitosmitos Jepang kuno disebutkan bahwa Saruta Biko bertugas menjadi mediator antara dewa dan manusia atau khayangan dan bumi. Menurut Folker (1977: 120), Saruta Biko adalah dewa penjaga pintu gerbang bumi dan dia lah yang digambarkan sebagai ikon dari sanzaru.

Merujuk pada hal tersebut maka sangat dimungkinkan bahwa masyarakat Jepang mengambil kata saruuntuk mengungkapkan konsep kesakralan yang identik dengan dewa. Menurut Volker (1975:120), kata saru yang juga mempunyai arti 'menghindar' mungkin mempunyai hubungan dengan ketiga gabungan kata tersebut. Dalam sanzaru, ada filosofi mizaru, kikazaru dan iwazaru. Mizaru yang berasal dari kata miru 'melihat' dan saru 'menghindar' dapat diartikan sebagai menghindari atau tidak melihat hal-hal yang buruk. Kemudian kikazaru yang berasal dari kata kiku 'mendengar' dan saru 'menghindar' dapat diartikan sebagai menghindari atau tidak mendengarkan hal-hal yang buruk. Terakhir, iwazaru yang berasal dari kata iu 'bicara' dan saru 'menghindar' dapat diartikan sebagai menghindari atau tidak bicara hal-hal yang buruk. Ketiga hal tersebut menunjukkan suatu konsep kesucian yang juga melekat pada image seorang dewa.

Walaupun kata saru dalam ketiga konsep ajaran tersebut diartikan sebagai menghindar, namun penulisan -zaru dalam Bahasa Jepang pada ketiga konsep tersebut tetap menggunakan huruf Kanji yang melambangkan kata monyet. Huruf Kanjisaru yang berarti menghindar adalah 去る sedangkan yang berarti saru adalah 猿. Dalam kamus besar bahasa Jepang Kōjien, penulisan sansaru, misaru, 
kikasaru dan iwasaru secara berturut-turut adalah sebagai berikut: sansaru 三猿, mizaru 見猿, kikazaru 聞か猿, dan iwazaru 言わ猿. Merujuk pada huruf Kanji saru yang digunakan pada kata-kata tersebut, jelas dapat diketahui bahwa monyet dijadikan simbol yang merepresentasikan dewa. Maka dalam hal ini, saru digunakan sebagai ranah sumber untuk menjelaskan kesucian sebagai ranah targetnya. Dalam hal ini monyet sebagai dewa yang bebas dari berkata, melihat, mendengar hal buruk dianggap pas untuk menjelaskan konsep kesucian dalam ajaran agama Shinto.

\section{b. Monyet Sebagai Hewan yang Memiliki Kekuatan Magis}

Konsep pemikiran terhadap monyet sebagai hewan yang memiliki kekuatan magis terlihat dalam idiom sarugi, sarugutsuwa, sarushibari dan sarutsunagi. Dalam keempat idiom tersebut, kata saru diidentikkan dengan fungsi membuat sesuatu menjadi diam ataupun suatu keadaan tidak bebas untuk bergerak. Konsep pemikiran ini dilandasi oleh kepercayaan yang meyakini bahwa monyet adalah hewan yang mempunyai kekuatan untuk membuat sesuatu menjadi diam. Hal ini mungkin berasal dari pengalaman budaya yang terdapat di Jepang selama beribu-ribu tahun. Dalam literatur sejarah dikatakan bahwa masyarakat Jepang percaya jika monyet adalah hewan yang memiliki kekuatan supranatural untuk menjaga dan menjinakkan kuda. Kepercayaan ini terutama berkembang pada zaman Heian (794 - 1185 M) hingga zaman Edo (1600$1867 \mathrm{M})$.

Sejak dahulu, monyet dipercaya mempunyai hubungan yang erat dengan kuda. Kuda adalah kendaraan bagi dewa, dan monyet yang bertugas sebagai mediator berfungsi untuk menjaga dan menjinakkan kendaraan para dewa. Untuk itu, monyet sering diikatkan ke kandang kuda ataupun di dekat kawanan kuda untuk menjaga dan menjinakkannya. Baik kuda maupun monyet, keduanya mempunyai kedudukan penting dalam kepercayaan masyarakat Jepang. Kuda dipercaya sebagai kendaraan para dewa untuk turun dari gunung, sedangkan monyet dipercaya sebagai kaki tangan dewa yang mempunyai kekuatan supranatural untuk menjaga kuda yang tugasnya antara lain adalah untuk menjinakkan, menghindarkannya dari penyakit serta menyembuhkan penyakit (Hirose, 1989:81).

Kepercayaan tentang kekuatan supranatural monyet untuk menjaga kuda ditenggarai berasal dari India yang kemudian menyebar ke Cina dan akhirnya meluas hingga ke Jepang (Murasaki, 1991: 7). Topeng berbentuk monyet, jimat berbentuk kepala monyet maupun monyet dipercaya mempunyai kekuatan supranatural untuk keselamatan kuda. Monyet yang diikatkan di tiang dan diletakkan di dekat kawanan kuda dipercaya dapat menjinakkan dan menyembuhkan kuda melalui kekuatan magisnya (Yanagita via Ohnuki-Tierney, 1984:281). Dalam sebuah kitab bernama Ryojin Hisho yang dibuat pada zaman Heian, terdapat puisi yang berjudul Shirabyoushi. Puisi ini menggambarkan pemandangan seekor monyet yang dipelihara di sebelah kandang kuda. Hal ini menunjukkan bahwa pada zaman Heian, kepercayaan terhadap kekuatan monyet untuk menjaga kuda sudah menyebar di masyarakat (Suo, 2003).

Topeng berbentuk monyet juga sering ditemukan tertempel di tiang kandang kuda sebagai manifestasi dari dewa monyet (Hirose, 1989: 70). Selain topeng berbentuk monyet, dewa monyet juga dimanifestasikan melalui patung berbentuk monyet. Patung-patung berbentuk monyet banyak ditemukan di dalam kandang-kandang kuda daerah Nikko. Masyarakat Nikko percaya bahwa 
pada malam tahun baru, patung-patung monyet yang mereka letakkan di dalam kandang kuda akan hidup dengan menggunakan pakaian ala pendeta Shinto. Monyet yang berpakaian ala pendeta agama Shinto tersebut dipercaya akan memberikan berkah kepada para pengikutnya(Volker,1975: 120).

Selain topeng dan patung berbentuk monyet, kepala monyet juga digunakan sebagai manifestasi dewa monyet. Penduduk di daerah Okayama sudah sejak lama mengadakan pemujaan terhadap kepala monyet. Mereka berharap kekuatan supranatural dari kepala monyet dapat memberikan keselamatan, ketenangan serta menghindarkan kuda yang mereka pelihara dari penyakit (Hirose, 1989:65-66). Monyet sebagai manifestasi lain dari dewa monyet sering digunakan terutama pada zaman Kamakura untuk menjaga kawanan kuda perang milik raja. (Hirose via Ohnuki-Tierney, 1984: 281-282). Sedangkan pada zaman Edo, pertunjukan monyet digunakan sebagai ritual tahunan untuk mendoakan kuda milik Shogun (Murasaki, 1991: 12)

Idiom sarugi yang bermakna 'pohon monyet' adalah istilah yang digunakan untuk tiang penambat kuda. Dalam idiom ini, monyet yang dipercaya memiliki kekuatan magis untuk menjinakkan kuda diambil sebagai ranah sumber untuk menjelaskan tiang penambat kuda sebagai ranah targetnya. Dalam hal ini relasi yang muncul di atara keduanya adalah bahwa monyet dan tiang sama-sama bisa digunakan untuk membuat kuda tetap diam di tempat.

Idiom sarugutsuwa yang memiliki arti literal kekang monyet merupakan istilah untuk alat penyumpal mulut. Dalam idiom ini, kata saru jugadigunakan sebagai ranah sumber untuk menjelaskan konsep membuat sesuatu menjadi diam dan terkendali. Monyet sebagai hewan magis digunakan sebagai ranah sumber untuk menjelaskan keadaan diam, yaitu keadaan yang dihasilkan saat seseorang disumpal mulutnya agar tidak bisa berbicara ataupun berteriak. Dalam hal ini, relasi antara monyet yang dipercaya sebagai hewan yang bisa menjinakkan kuda dengan alat penyumpal mulut adalah sesuatu yang bisa membuat sesuatu menjadi diam (jinak dan tidak rebut).

Dalam idiom sarushibari (ikatan) dan sarutsunagi (orang yang tangan kakinya terikat), kata saru juga menunjukkan konsep mengendalikan sesuatu agar menjadi diam dan terkendali. Hal ini sesuai dengan hal yang dijelaskan, yaitu keadaan seseorang yang tidak dapat bergerak (diam) karena tangan dan kakinya terikat. Kuda yang tenang terkendali karena ada monyet yang diikatkan di dekat kandangnya mempunyai kesamaan kondisi dengan sesuatu atau orang yang diikat.

\section{c. Monyet Sebagai Hewan yang Mirip Manusia}

Konsep monyet sebagai hewan yang merefleksikan sifat atau kelakuan buruk manusia terdapat dalam idiom Sarushibai, Sarujie, Sarumane, Saruni, Saruboo dan Sarugashikoshi. Monyet dijadikan ranah sumber dalam keenam idiom tersebut bisa jadi didasarkan pada hal di bawah ini. Pertama, pada faktanya, monyet memang menjadi salah satu bagian penting dan begitu familiar dalam kehidupan masyarkat Jepang. Hal ini mungkin disebabkan karena hanya ada satu spesies asli monyet Jepang, yaitu Nihonzaru (Macaca fuscata) alias Monyet Salju. Monyet ini mempunyai muka dan bokong yang merah, mata yang ekspresif, ekor yang pendek dengan tingginya berkisar antara 2 hingga 4 kaki, dan beratnya sekitar 22 hingga 66 pon (blueplanetbiomes.org, tanpa tahun). Kedua,karakter monyet sebagai hewan yang hidup secara berkelompok dinilai sama dengan ciri-ciri manusia yang juga merupakan makhluk sosial. Penghargaan masyarakat Jepang terhadap manusia sebagai makhluk sosial terlihat dalam huruf kanji yang membentuk kata 'ningen' yang berarti manusia. Huruf '人' sebagai 
Izumi, Volume 7 No 2, 2018

e-ISSN: 2502-3535, p-ISSN: 2338-249X

Tersedia online di http://ejournal.undip.ac.id/index.php/izumi

petanda 'nin' berarti 'orang', dan huruf '間' sebagai petanda 'gen' berarti 'di antara'. Oleh karena itu, di Jepang keberadaan monyet sangat dihargai karena kemiripan sifatnya dengan manusia (Ohnuki-Tierney, 1984: 2).Ketiga, menurut seorang pelaku sarumawashi (topeng monyet) bernama Kuro, jika dilihat dari fisiologisnya, monyet Jepang sangat merepresentasikan bentuk fisiologis orang Jepang, yaitu:

1. Memiliki badan yang kuat dan mampu bertahan pada cuaca panas maupun dingin.

2. Dalam posisi berdiri, monyet Jepang memiliki bentuk yang indah dengan torso yang panjang dan tangan serta kaki yang pendek. Menurut Kuro, bentuk tersebut mirip dengan bentuk tubuh orang Jepang sehingga mudah menimbulkan empati.

3. Jika dalam posisi duduk, monyet Jepang mempunyai postur yang tegak sehingga tercipta siluet yang indah (Murasaki, 1991: 165-166).

Secara umum, citra masyarakat Jepang memang sangat mirip dengan uraian di atas. Orang Jepang memiliki tubuh yang kuat dan tahan banting di segala cuaca. Orang Jepang juga kebanyakan memiliki bentuk tubuh yang indah dengan torso panjang dan tangan serta kaki yang pendek. Orang Jepang juga selalu duduk dengan tegak. Berdasarkan kesamaan tersebut, itulah yang kiranya menyebabkan monyet dianggap sebagai figur yang sangat pas untuk merefleksikan manusia, dalam hal ini manusia Jepang.

Dibandingkan dengan dua konsep sebelumnya, konsep monyet sebagai hewan lelucon yang merefleksikan sifat dan kelakuan buruk manusia adalah konsep yang paling baru. Konsep ini baru muncul kira-kira pada zaman AshikagaMuromachi (1334-1599). Hal ini diketahui karena pada zaman tersebut mulai muncul pertunjukan monyet (sarumawashi) atau yang di Indonesia lebih sering disebut dengan pertunjukan Topeng Monyet. Sumber sejarah yang menyebutkan adanya pertunjukan monyet pada zaman ini adalah dokumen Yuzu Nenbutsu Engi Emaki, yangbertanggal tahun 1391. Dokumen tersebut mengilustrasikan pemandangan seekor monyet yang sedang berdiri pada kaki belakangnya sedang melakukan pertunjukan dengan seorang pelatih yang ditonton oleh beberapa orang. Dalam dokumen itu digambarkan monyet dan pelatihnya sama-sama tidak memakai pakaian bagus. Monyet dan pelatihnya sama-sama bertelanjang kaki (OhnukiTierney, 1984:282). Monyet yang berpakaian layaknya sang pelatih dalam ilustrasi dokumen tersebut menunjukkan bahwa pada zaman itu, monyet telah dianggap mirip seperti manusia.

Dalam idiom sarujie yang memiliki arti pemikiran yang nampak meyakinkan dari luar, kata saru digunakan untuk menjelaskan kebodohan manusia. Dalam hal ini, monyet digunakan untuk menggambarkan kebodohan. Monyet yang dapat meniru manusia bagaimanapun bukanlah manusia. Monyet yang sedang melakukan pertunjukan hanya terlihat pintar dari luar, sedangkan dalamnya hanyalah tetap seekor monyet yang tidak mempunyai akal pikiran. Relasi persamaan yang digambarkan dalam idiom ini adalah bahwa manusia pun kadang hanya nampak meyakinkan dari luarnya saja, tidak ubahnya seperti seekor monyet yang nampak meyakinkan saat sedang meniru manusia.

Dalam idiom sarugashikoshi yang berarti kecerdasan yang licik, kata saru digunakan untuk menjelaskan konsep kelicikan. Dalam hal monyet sebagai hewan yang bisa meniru manusia dianggap sebagai hewan yang pintar. Namun, monyet hanya melakukan berbagai aksi untuk mendapatkan makanan.Dalam hal ini, monyet ranah sumbernya mempunyai relasi kesamaan dengan sifat manusia sebagai ranah targetnya, yaitu sifat 
manusia yang suka menggunakan kecerdasannya untuk kelicikan saja.

Dalam idiom sarushibai yang berarti pertunjukkan yang buruk atau perencanaan yang buruk, penggunaan kata sarudidasarkan oleh dua konsep pemikiran yaitu: 1.) Monyet adalah hewan yang sering digunakan dalam pertunjukan hiburan. Sebaik-baiknya pertunjukkan monyet, tetap saja pertunjukan tersebut hanyalah pertunjukan yang dilakukanoleh hewan yang tak berakal. 2.) Seberapapun pandainya, monyet hanyalah hewan yang tak berakal. Dari asumsi pertama, relasi yang dibangun kata saru sebagai ranah sumber dengan manusia sebagai ranah targetnya adalah suatu kegagalan seseorang dalam membuat suatu pertunjukan sehingga menghasilkan pertunjukan yang buruk. Pertunjukan yang demikian kemudian dianggap sama dengan pertunjukan yang dilakukan oleh monyet yang tak berakal. Dari asumsi yang kedua, relasi kesamaan yang dibangun adalah kedangkalan pemikiran. Manusia yang berpikiran dangkal tidak bisa membuat suatu perencanaan yang baik. Hal itu sama saja seperti monyet yang merupakan hewan tidak berakal yang tentu saja tidak dapat membuat perencanaan.

Dalam idiom saruni yang berarti terlihat seperti saudara kembar walaupun bukan saudara, monyet digunakan sebagai ranah sumber untuk merepresentasikan fenomena yang ada di dunia manusia. Monyet sering dianggap mirip dengan manusia. Namun walaupun demikian monyet tetaplah bukanlah manusia. Hal ini kemudian diambil untuk menggambarkan fenomena dua orang yang mirip namun bukan saudara.

Dalam idiom saruboo, pipi monyet digunakan sebagai ranah sumber untuk merefleksikan pipi manusia yang membesar karena rakus mengunyah makanan terlalu banyak. Monyet digambarkan sebagai hewan yang rakus, sehingga cocok untuk merefleksikan pipi yang membesar karena makanan.
Dalam idiom sarumanekata saru digunakan untuk menjelaskan konsep "meniru tanpa berpikir". Dalam hal ini, monyet dipandang sebagai hewan yang yang bisa menirukan manusia tapi tidak mempunyai pemikiran. Manusia yang suka menirukan orang lain tanpa berfikir apapun dianggap mirip dengan monyet. Oleh karena itu, dalam idiom ini, monyet dan manusia mempunyai kesamaan sifat yaitu suka meniru tanpa berfikir.

\section{SIMPULAN}

Idiom 'saru' dalam Bahasa Jepang merupakan suatu set simbolik untuk merepresentasikan pengetahuan dan pengalaman masyarakat Jepang terhadap hal-hal yang bersifat abstrak. Idiom-idiom tersebut berawal dari metafora-metafora yang telah digunakan terus-menerus sehingga menjadi memiliki arti leksikal yang penggunaannya ditetapkan berdasarkan kesepakatan. Untuk mengetahui konsep awal yang mendasari idiom-idiom tersebut, maka idiom-idiom tersebut harus dilihat dari sudut pandang diakronisnya, atau dikembalikan ke arti metaforisnya

Berdasarkan arti leksikalnya sebagai idiom, secara umum idiom-idiom yang menggunakan kata saru 'monyet' dalam bahasa Jepang memiliki tiga makna yang berbeda, yaitu hal yang berhubungan dengan dewa, hal yang berhubungan dengan membuat sesuatu menjadi diam dan hal yang berhubungan dengan sifatsifat manusia. Dari hubungan makna literal dan metaforis idiom-idiom tersebut, dapat dilihat cara pandang orang Jepang terhadap monyet, yaitu (1) sebagai hewan yang suci atau sakral, (2) sebagai hewan yang memiliki kekuatan magis untuk membuat sesuatu menjadi diam, dan (3) sebagai hewan yang mirip dengan manusia.

Pandangan masyarakat Jepang terhadap monyet sebagai hewan yang sakral dilandasi dari suatu kepercayaan yang telah ada sejak beribu tahun lalu terhadap dewa monyet. Konsep pemikiran ini tertuang dalam idiom sansaru yang memiliki arti 
tiga perintah dewa yang direpresentasikan dalam bentuk dewa monyet.

Konsep monyet sebagai hewan yang memiliki kekuatan magis untuk membuat sesuatu menjadi tidak bergerak atau diam dilandasi dari keprcayaan terhadap monyet yang memiliki kekuatan supranatural untuk menjinakkan kuda. Dalam hal ini menjinakkan berarti mengatur atau mengontrol kuda supaya tetap diam. Konsep ini tertuang dalam idiom Sarugi (tiang penambat), Sarugutsuwa (alat sumpal mulut), Sarushibari (jenis ikatan) dan Sarutsunagi (orang dalam keadaan tangan dan kaki terikat).

Konsep monyet sebagai hewan yang mirip dengan manusia dilandasi dari pengalaman dan pengetahuan orang Jepang mengenai manusia. Dalam pemikiran orang Jepang, manusia bisa bersifat licik, rakus, dangkal dan bodoh. Manusia jugaterkadang terlihat mirip dengan manusia lainnya walaupun mereka bukanlah saudara. Kelicikan manusia tertuang dalam idiom sarujie, kedangkalan dan kebodohan manusia tertuang dalam sarugashikoshi sarumane dan sarushibai, kerakusan manusia tertuang dalam saruboo dan kemiripan manusia dengan manusia lain tertuang dalam saruni.

\section{DAFTAR PUSTAKA}

Admin. (tanpa tahun). Japanese Macaque. Dalam http://www.blueplanetbiomes.org/japan ese_macaque.htm. Diakses tanggal 3 Januari 2018

Admin. (2003). "Sarumawashi no Nenpu". Dalam http://www.suo.co.jp/10suo/ chronology/. Diakses tanggal 5 Desember 2017 pukul 20.00

Bilig, Michael. (2005). 'Metaphor, Idiom and Ideology: The Search for 'No Smoking Guns', Discourse and Society. Vol. 16 (4). Hal. 459-480
Duranti, Alessandro.(1997). Linguistic Anthropology. Cambridge: Cambridge University Press

Dyah, Retno. (2017). Idiom Bahasa Jepang yang Menggunakan Nama Hewan. Dalam http://eprints.undip. ac.id/56363/. Diakses tanggal 18 September 2018 pukul 20.00

Foley, William. (1997). Anthropological Linguistics: An Introduction. Sydney: Blackwell Publishers Ltd

Hartati, Umi. (2002). Thesis. Idiom dalam Bahasa Indonesia. UGM: tidak diterbitkan

Hirose, Shizumu. (1989). Saru to Nihonjin: Kokoro ni Ikiru Saru Tachi. Tokyo: Daiichi Shobo

Murasaki,Yoshimasa.(1991). Sarumawashi Sen Nen no Tabi. Japan: Setsuko Murasaki

Ohnuki, Emiko-Tierney. (1984). Monkey Performances: A Multiple Structure of Meaning and Reflexivity in Japanese Culture. Washington DC: American Ethnological Society

Volker, T. (1975). The Animal in Far Eastern Art. Leiden: Netherlands

Mayer, Fanny Hagins. (1981). 'Flora and Fauna In Japanese Folk Tale'. Asian Folklore Studies.Vol 40. No 1. Hal. 2332

Ohnuki-Tierney, Emiko. (1984). 'A Monkey As Mirror. Symbolic Transformations in Japanese History and Ritual'.In Text, Play, and Story: The Construction and Reconstruction of Self and Society. American Ethnoogical Society. Hal. 278-313 
Izumi, Volume 7 No 2, 2018

e-ISSN: 2502-3535, p-ISSN: 2338-249X

Tersedia online di http://ejournal.undip.ac.id/index.php/izumi

Palandi, Esther Hesline. (2013). 'Analisis Metafora Bahasa Jepang: Dimensi Sosiokultural Bangsa Jepang dalam Retorika Berbahasa'. Prosiding Seminar Internasional Studi Bahasa Dari Berbagai Perspektif Dalam Rangka Ulang Tahun ke-80 Prof. Dr. Soepomo Poedjosoedarmo. Hal. 260269

Prayogi, Icuk. (2013). 'Bentuk-Bentuk Metafora Temporal Bahasa Indonesia (Tinjauan Awal)'. Prosiding Seminar Internasional Studi Bahasa Dari Berbagai Perspektif Dalam Rangka Ulang Tahun ke-80 Prof. Dr. Soepomo Poedjosoedarmo. Hal. 776-784

Setyari, Agustina Dewi. (2007). Thesis. Penyandra Bentuk Tubuh Indah Dalam Masyarakat Jawa. UGM: Tidak Diterbitkan

Shoten, Iwanami. (2009). Kōjien. Dairokupan. Gyakuhiki Kensaku Taiou. Japan: Iwanami Shoten

Shu, Fen Chen dan Li, Chi Lee Chen. (2011). 'What Animals Reveal about Grammar and Culture: A Study of Animal Metaphors in Mandarin Chinese and English'. 師大學報：語 言與文學類 (Journal of Teacher's University: Language and Literatur). Vol 56. No 2. Hal. 121-152
Wijana, I Dewa Putu. (2013). 'Gadjah Mada Bercanda, Humor Dosen UGM: Sebuah Kajian Sosiopragmatik'. Prosiding Seminar Internasional Studi Bahasa Dari Berbagai Perspektif Dalam Rangka Ulang Tahun ke-80 Prof. Dr. Soepomo Poedjosoedarmo. Hal. 22-38

Yasuo, Kitahara. (2009). Meikyō Kokugo Jiten. Japan: Taishukan Shoten 